UDC 621.3 .051

\title{
Simulation Model for Drivability Assessment and Optimization of Hybrid Drive Trains
}

\author{
M. Domijanic ${ }^{1)}$, M. Hirz ${ }^{1)}$ \\ ${ }^{1)}$ Graz University of Technology (Graz, Republic of Austria) \\ (C) Белорусский национальный технический университет, 2021 \\ Belarusian National Technical University, 2021
}

\begin{abstract}
The growing electrification of vehicle drive trains is increasing their complexity significantly. The interactions between the different drive train components should not be noticed negatively by the occupants, which is considered as good drivability and thus contributes to increasing customer acceptance. Today's development processes of hybrid- and electric driven cars consider energy management in earlier development phases as drivability optimization. In these early development phases, fuel- and energy consumption are optimized on the basis of standardized driving cycles. Drivability aspects and influences of real driving operation are not integrated until the prototype phase. In this way, modifications of drivabilityrelevant aspects phase are limited, which restricts the potential to find optimal solutions. In this context, the submitted paper presents an approach for assessment and optimization of the drivability of hybrid drive trains in the virtual development process. The created simulation model is exemplarily based on the P2-hybrid drive train of a VW Passat GTE. For the validation of the drive train model and the assessment of drivability, defined maneuvers were carried out on a test track and compared with the results of maneuver simulations. By simulating different driving maneuvers, the resulting acceleration oscillations, which affect the passenger, are calculated and evaluated from the aspect of drivability. The assessment method is derived from a VDI directive dealing with the effects of vibrations on the wellbeing and human health. In order to identify the influencing factors of different maneuvers and parameters of the drive train components, both were varied in the study. It turned out that change of gears and closing of the clutch had the greatest influence on the drivability and thus has the greatest potential for optimizing design and control strategy of hybrid drive trains. In this way, the presented approach enables the assessment and optimization of drivability of hybrid drive trains in the early development phase and thus reduces the gap between virtual development and prototype phase.
\end{abstract}

Keywords: hybrid drive train, drivability, development process, operating strategy, vehicle simulation

For citation: Domijanic M., Hirz M. (2021) Simulation Model for Drivability Assessment and Optimization of Hybrid Drive Trains. Science and Technique. 20 (1), 37-44. https://doi.org/10.21122/2227-1031-2021-20-1-37-44

\section{Имитационная модель для оценки управляемости автомобилем и оптимизация гибридной силовой установки}

\author{
Инж. М. Домиянич ${ }^{1)}$, канд. техн. наук, доц. М. Хирц ${ }^{1)}$ \\ ${ }^{1)}$ Грацский технический университет (Грац, Австрийская Республика)
}

Реферат. Растущая электрификация силовых установок автомобилей существенно повышает их сложность. Совместная работа различных компонентов трансмиссии не должна быть замечена водителями и пассажирами, что рассматривается как хорошая управляемость и таким образом способствует росту удовлетворения требований потребителя. В настоящее время процесс разработки автомобилей с гибридным и электрическим приводом предполагает, что управление энергопотреблением - это элемент оптимизации управляемости транспортного средства. На ранних этапах разработки потребление топлива и энергии можно совершенствовать с помощью стандартизированных циклов

\begin{tabular}{ll}
\hline Адрес для переписки & Address for correspondence \\
Домиянич Марко & Domijanic Marko \\
Грацский технический университет & Graz University of Technology \\
ул. Инффельдгассе, 11/2, & $11 / 2$, Inffeldgasse str., \\
8010, г. Грац, Австрийская Республика & 8010 , Graz, Republic of Austria \\
Тел.: +43 316 873-352-55 & Tel.: +43 316 873-352-55 \\
domijanic@tugraz.at & domijanic@tugraz.at
\end{tabular}


вождения. Аспекты управляемости и влияние реального процесса вождения не рассматриваются вплоть до этапа разработки и испытаний опытного образца. Таким образом, варианты аспектов, имеющих отношение к управляемости, весьма ограничены, что снижает потенциал для принятия оптимальных решений. Исходя из этого в данной статье представлен подход к оценке и оптимизации управляемости гибридных приводов с помощью виртуальной разработки. В качестве примера создана имитационная модель, основанная на P2-гибридной трансмиссии VW Рassat GTE. $\mathrm{C}$ целью оценки правильности модели трансмиссии и управляемости проведены определенные мероприятия на испытательном полигоне, которые затем сравнивались с результатами моделированных маневров. Моделируя различные маневры вождения, результирующие колебания ускорения, влияющие на пассажира, рассчитываются и оцениваются с точки зрения управляемости. Метод оценки основывается на рекомендациях Ассоциации немецких инженеров (VDI), учитывающих влияние вибраций на здоровье человека. Для выявления определяющих факторов при изучении разных маневров и параметров компонентов трансмиссии в исследованиях анализировались и маневры, и параметры. Определено, что смена передач и включение сцепления оказывают максимальное влияние на ходовые характеристики транспортного средства и поэтому обладают наивысшим потенциалом для проведения оптимизации конструкции и стратегии управления гибридными трансмиссиями. Таким образом, предлагаемый подход позволяет оценить и оптимизировать управляемость гибридных приводов на ранней стадии разработки. Тем самым сокращается период времени между виртуальной разработкой и этапом создания прототипа.

Ключевые слова: гибридная силовая установка, управляемость, процесс разработки, стратегия эксплуатации, моделирование транспортного средства

Для цитирования: Домиянич, М. Имитационная модель для оценки управляемости автомобилем и оптимизация гибридной силовой установки / М. Домиянич, М. Хирц // Наука и техника. 2021. T. 20, № 1. C. 37-44. https://doi.org/ $10.21122 / 2227-1031-2021-20-1-37-44$

\section{Introduction}

Due to the increasing electrification of vehicle drive trains, their control complexity increases significantly. For instance, the drive train of a hybridelectric vehicle is considerably more complex in comparison to a vehicle driven only by an Internal Combustion Engine (ICE). However, the complex algorithms for drive train control, which influence the dynamics vehicle behavior, should not be perceived by the passengers, which is then regarded as good drivability or driving comfort.

The development and optimization of the operating strategy is an essential factor in achieving optimum energy- respectively fuel consumption. A range-optimized operating strategy depends on various external factors, such as route profile, driving style and drivability. State-of-the-art in vehicle development processes of electrified vehicles (xEVs) is to consider energy management decoupled from drivability (Fig. 1).

In the early development phase, energy management is developed and optimized on the basis of standardized driving cycles (e. g. NEDC, WLTP). Drivability aspects as well as influences of real driving operation are not integrated until the prototype phase [1]. In this early development phases, the operating strategy of xEVs is often designed purely for optimum fuel-, respectively energy consumption. Later in the development process, prototypes are used to investigate the impact of the operating strategy on drivability. The possibilities for modifications in these later development phases are limited and an optimal solution is in most cases no longer possible [2].

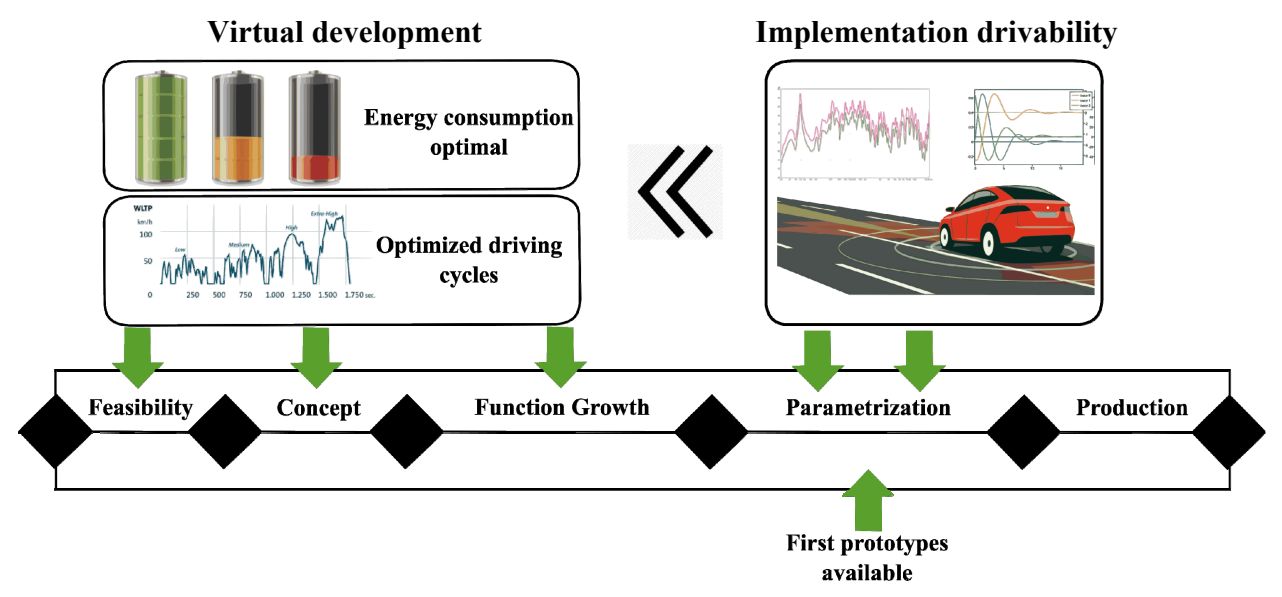

Fig. 1. State-of-the-art vehicle development process [1] 
In this publication, an approach is presented for assessment and optimization of drivability (comfort and performance) of hybrid drive trains within the virtual development process. With the presented methods the gap in the development process between virtual concept and prototype-based development shall be closed.

In the first step, specific driving maneuvers for the objective assessment of drivability were defined. For the measurements and modelling of an exemplary hybrid drive train, a P2-hybrid drive train configuration of a VW Passat GTE [3] was selected. In order to validate the developed simulation model, comprehensive measurements were carried out on public roads and on a test track. The simulation model was then validated and parameterized on the basis of the generated measurement data. Subsequently, parameters of drive train components were varied to understand their influence and optimization potential on drivability.

Drivability assessment. Drivability is generally defined as the impact of various vehicle characteristics on the driver and/or passengers. This includes vehicle dynamics, e. g. response behavior, shifting behavior and load-change behavior [4].

The terms driving comfort and drivability are often used in a similar context. Nevertheless, driving comfort is defined as the absence of discomfort [5]. The determination of driving comfort is based on a subjective evaluation, i. e. different drivers experience comfort differently. Drivability, on the other hand, is based on an objective assessment process, which is evaluated by characteristic parameters such as vehicle acceleration, response, etc. [6]. Fig. 2 shows the main influencing factors on driving comfort [6].

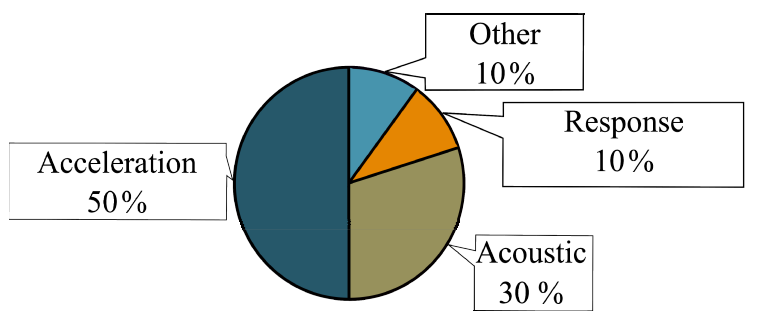

Fig. 2. Main factors influencing driving comfort [6]

The drive train, consisting of engine(s), gearbox(es), traction components, wheels, etc., has a particular influence on drivability [5]. The accele- rations and oscillations caused by the drive train affect the driver (normally seated) at different locations and with different intensity. In general, drivability is assessed as subjective perception, making it technically difficult to measure. The subjective assessments are usually carried out by trained personnel or by test persons. For the subjective assessment of drivability, a grading scale has been established in which grades from 1 to 10 are awarded for specific occurrences.

Due to the subjective character of such assessment systems, attempts are made to find objective measurement methods for assessing driving comfort. Accelerations of the vehicle are transferred by the chassis to the driver's seat, where the driver perceives these accelerations mainly via the backrest.

The assessment and effect of acceleration vibrations on humans are comprehensively described in the VDI Guideline 2057 Sheet 1 [7] as the basic guideline for whole-body vibrations. In this guideline, whole-body vibrations are defined as vibrations in the frequency range from $0.1 \mathrm{~Hz}$ to $80 \mathrm{~Hz}$. Experiments have shown that the relevant frequency range for the determination of effects on humans is between $0.1 \mathrm{~Hz}$ and $30 \mathrm{~Hz}$ [6]. In general, the VDI 2057-1 standard defines a calculated driving comfort index or vibration comfort value which is compared with a subjective table in order to determine the subjectively experienced ride. Tab. 1 shows the relationship between the calculated comfort value and the subjective perception according to the VDI 2057-1 guideline.

Table 1

Relationship between calculated comfort value and the subjective perception [7]

\begin{tabular}{|c|c|}
\hline $\begin{array}{c}\text { Vibration total } \\
\text { value, } \mathrm{m} / \mathrm{s}^{2}\end{array}$ & $\begin{array}{c}\text { Description } \\
\text { of perception }\end{array}$ \\
\hline$<0.010$ & Not noticeable \\
\hline 0.015 & Perception threshold \\
\hline 0.020 & Just noticeable \\
\hline 0.080 & Noticeable \\
\hline 0.315 & Strongly noticeable \\
\hline$>0.315$ & Very strongly noticeable \\
\hline
\end{tabular}

Several OEMs (Original Equipment Manufacturers) and suppliers have developed their own 
methods for the objective assessment of drivability. Audi, for instance, uses the Ride meter tool to assess the chassis regarding vibration comfort [8]. A commercial available assessment tool for drivability was introduced in 1998 by AVL List $\mathrm{GmbH}$ under the name AVL-DRIVETM [9]. The AVL-DRIVETM system makes it even in the prototype phase of vehicle development possible to assess how the vehicle reacts to the driver and vice versa, how the driver perceives the driving experience.

In order to objectively assess drivability, maneuvers are necessary that represent the main driving situations for comfort and performance assessment. For that reason, maneuver plans have been developed and assigned to the categories: acceleration maneuvers, drive away, constant speed, gear shifts, Tip-In and Tip-Out. In addition, objective drivability criteria and the associated measurable parameters were defined. Tab. 2 shows pre-defined driving maneuvers according to [10].

Table 2

\begin{tabular}{|l|c|c|}
\multicolumn{4}{|c}{$\begin{array}{c}\text { Maneuver plans and objective criteria } \\
\text { for drivability assessment [10] }\end{array}$} \\
\hline Maneuver & Sub maneuver & Criteria \\
\hline Acceleration & Full load 0-100 km/h & Response \\
\cline { 2 - 3 } & Elasticity & Acceleration gradient \\
\hline Const. speed & Idle driving & Speed fluctuations \\
\cline { 2 - 3 } & Part load & Vibrations \\
\hline Drive away & Hill start & Acceleration peak \\
\cline { 2 - 3 } & Normal start & Initial bump \\
\hline Tip-In & After constant speed & Jerks \\
\cline { 2 - 3 } & Short Tip-In & Response delay \\
\hline Tip-Out & After acceleration & Jerks \\
\cline { 2 - 3 } & After constant speed & Initial bump \\
\hline Gear shift & $\begin{array}{c}\text { Downshift during } \\
\text { braking }\end{array}$ & Shift duration \\
\cline { 2 - 3 } & Downshift after \\
kick down & Shift delay \\
\hline
\end{tabular}

\section{Drive train modelling and validation}

Parameter determination. In order to provide accurate statements regarding drivability within a virtual (simulation-) environment, it is necessary to parameterize the vehicle model as exactly as possible. For this reason, comprehensive measurements were carried out with the reference vehicle.
Due to the complex P2-hybrid architecture of the drive train, high effort was required for parameter determination.

For the pitching model, which is required to simulate vehicle movements in the longitudinal direction, spring and damper parameters were experimentally determined and the chassis characteristics were parameterized according to [11]. For a proper re-production of brake maneuvers, the relationships between brake pressure and brake force on the front and rear wheels were analyzed. The validation of the measurement approach was carried out by simulating the braking maneuvers listed in Tab. 2 with a longitudinal dynamic vehicle model. In addition, the position and height of the center of gravity was determined by measurement.

The analysis of various driving cycles has shown that the drive train operating strategy of the reference vehicle includes a high number of switch-off and switch-on sequences as well as combined operating states of the two traction motors (electric motor and combustion engine). With the available measurement equipment, it was not possible to record the various operating states of the drive train with sufficient accuracy. For this reason, the operating strategy of the hybrid vehicle could not be described and examined in greater detail. Nevertheless, it was possible to record relevant dynamics data of the vehicle reaction with sufficient accuracy for performing the drivability assessment in the required precision.

Drive train modelling. The simulation model was developed to reproduce the following vehicle behavior: longitudinal dynamics for performance evaluation; combined vertical and longitudinal dynamics for comfort evaluation. In the first step, an existing model of a P2-hybrid drive train in the simulation environment LMS AMESim [12] was adapted to the drive train of the reference vehicle and parameterized with data acquired from measurements.

Fig. 3 shows the developed drive train model containing the following components: driver model, internal combustion engine model, electric motor/ generator model, transmission model, clutch model, battery model, vehicle model and hybrid operating strategy. The modelled P2-hybrid drive train consists of components, which interact with each other and can reproduce real driving behavior with sufficient accuracy. 


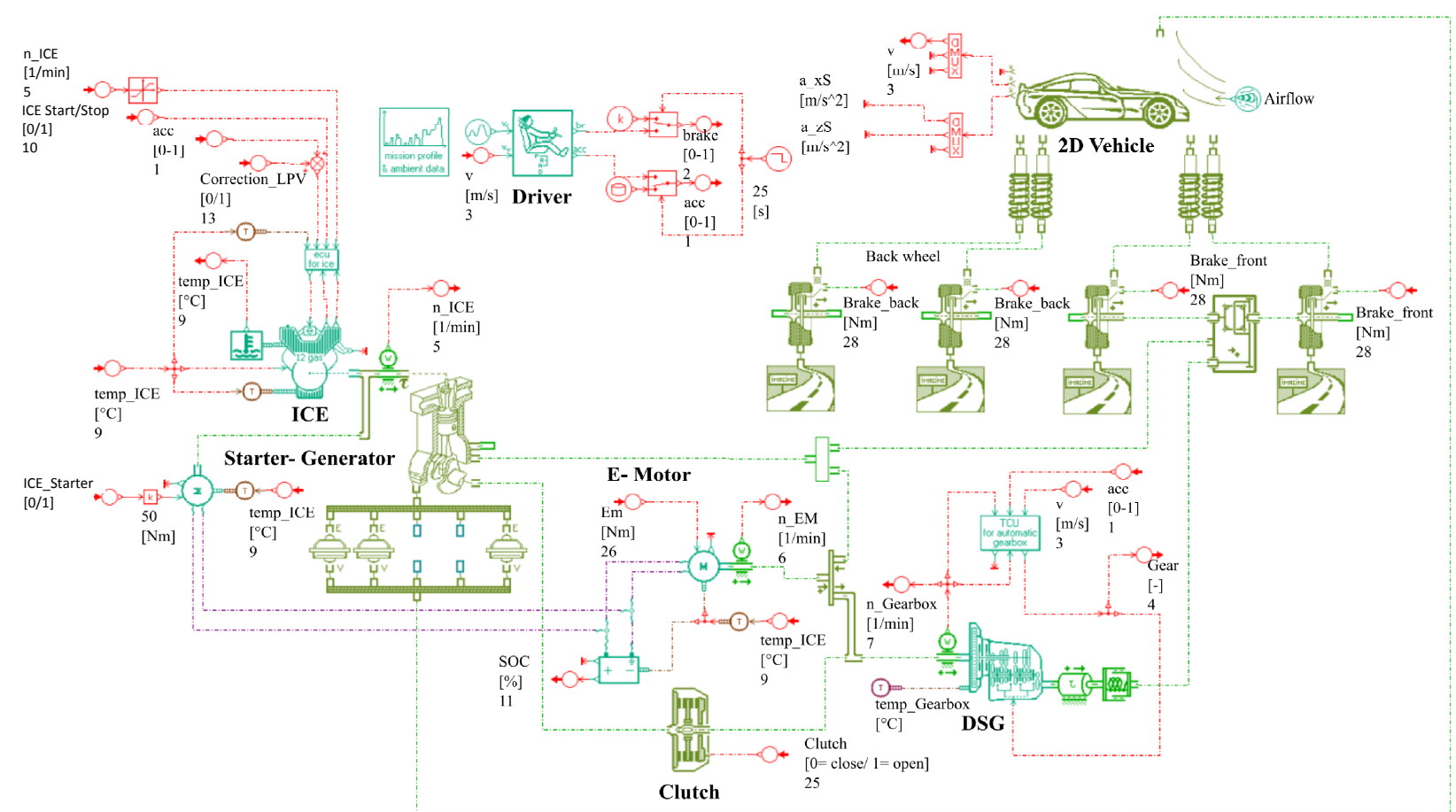

Fig. 3. P2-hybrid drive train model of VW Passat GTE [13]

Validation of the simulation model. In order to verify whether the modelled drive train demonstrates a behavior that correlates with a real vehicle, driving maneuvers were simulated in the simulation model and compared with measurement data collected during pre-defined driving maneuvers performed with a corresponding car.

Firstly, all drivability-relevant maneuvers listed in Tab. 2 were carried out on public roads and on a test track. For the measurements, the CAN-Bus (Controller Area Network) of the reference vehicle was recorded and the inertial measurement technology ADMA (Automotive Dynamic Motion Analyzer) [14] was used. The data was recorded using a Dewetron [15] measurement computer.

As input torque for the simulations, the delivered information about the system torque output, recorded during the test drives, was used, which represents the combined driving torque provided by both electric motor and ICE. Subsequently, the behavior of the modelled drive train was analyzed in comparison to the experimental results.
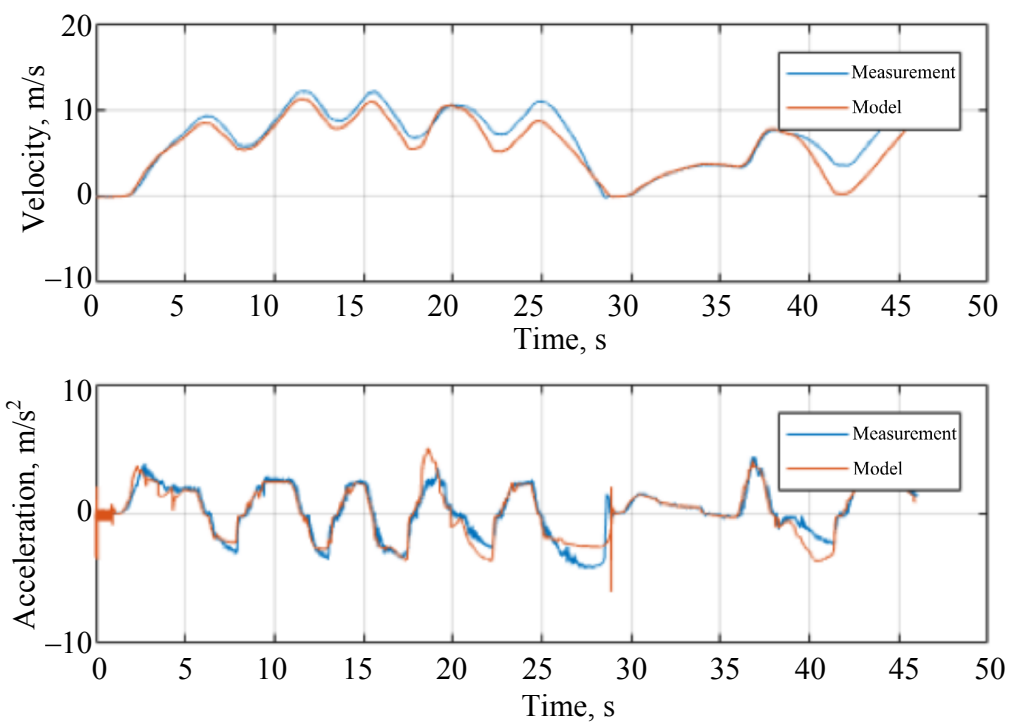

Fig. 4. Validated maneuvers - normal start, creep, rolling stop, vehicle stop [16] 
Fig. 4 shows the validated maneuvers - normal start, creep, rolling stop, vehicle stop as a comparison of measured and simulated vehicle speed and acceleration. The (small) discrepancies between measurement and simulation velocity shown in Fig. 4 are primarily due uncertainties in modelling of the brake system. Due to the fact, that the present research focusses on the propulsion system, the influence of the brake on the drivability can be neglected.

\section{Virtual drivability assessment}

Based on the simulation model, virtual drivability assessment of the conducted driving maneuvers was carried out. Considered were driving maneuvers listed in Tab. 2, where by the simulation was performed in several variations. The drivability assessment of the simulation model was carried out with the evaluation method according to VDI 2057-1.

In the first step, throttle pedal position, velocity and SoC (State of Charge) of the battery were changed in order to recognize possible influence of the execution of a driving maneuver on drivability relevant aspects.

Following, a Tip-In maneuver is exemplary analyzed. The Tip-In maneuver was carried out with variation of the initial velocity. This maneuver was conducted at $30,50,70,100$ and $130 \mathrm{~km} / \mathrm{h}$. In this scenario, the throttle pedal was pressed fully at a rate of $100 \%$ per second. The resulting accelerations at the seat rail for the Tip-In at $30 \mathrm{~km} / \mathrm{h}$ maneuver (starts at $35 \mathrm{~s}$ ) are shown in Fig. 5.

At higher velocities, the accelerations look similar, but occur in an extended form. This is due to the greater acceleration potential of the vehicle at $30 \mathrm{~km} / \mathrm{h}$ compared to higher speeds. The full actuation of the pedal therefore produces the highest accelerations. At approximately 37.2 s, a further increase in acceleration can be seen, which can be explained by the activation of the Boosting function. The calculated comfort values (Tab. 1) of the five velocity variants are 1.798 for the Tip-In at $30 \mathrm{~km} / \mathrm{h}, 1.344$ at $50 \mathrm{~km} / \mathrm{h}, 0.916$ at $70 \mathrm{~km} / \mathrm{h}$, 0.707 at $100 \mathrm{~km} / \mathrm{h}$ and 0.325 at $130 \mathrm{~km} / \mathrm{h}$. All of the occurring oscillations in the drive train are therefore very strongly noticeable. However, it can be seen that as the velocity increases also the driving comfort increases, which is due to the lower gear ratios at higher gears. As has already been the case in other maneuvers, gear shifts at low gears cause higher oscillations and must therefore be considered as an influencing factor for Tip-In maneuvers.

Other analyzed maneuvers were full-throttle acceleration from $0 \mathrm{~km} / \mathrm{h}$ to $100 \mathrm{~km} / \mathrm{h}$, normal start, downshifting during braking, upshifting during part load acceleration and Tip-Out after constant speed. By simulating and assessing the various driving maneuvers, occurrences that are responsible for the oscillations in the drive train were detected. It turned out that gear changes at high gear ratios produce high acceleration amplitudes in the driver's seat rail and thus are crucial for the assessment of drivability. The transition between hybrid and electric driving was also a trigger for peaks in the acceleration signal. In general, change of gears and closing of the clutch had the greatest influence on the drivability and thus the highest optimization potential for the hybrid drive train in the virtual development phase.
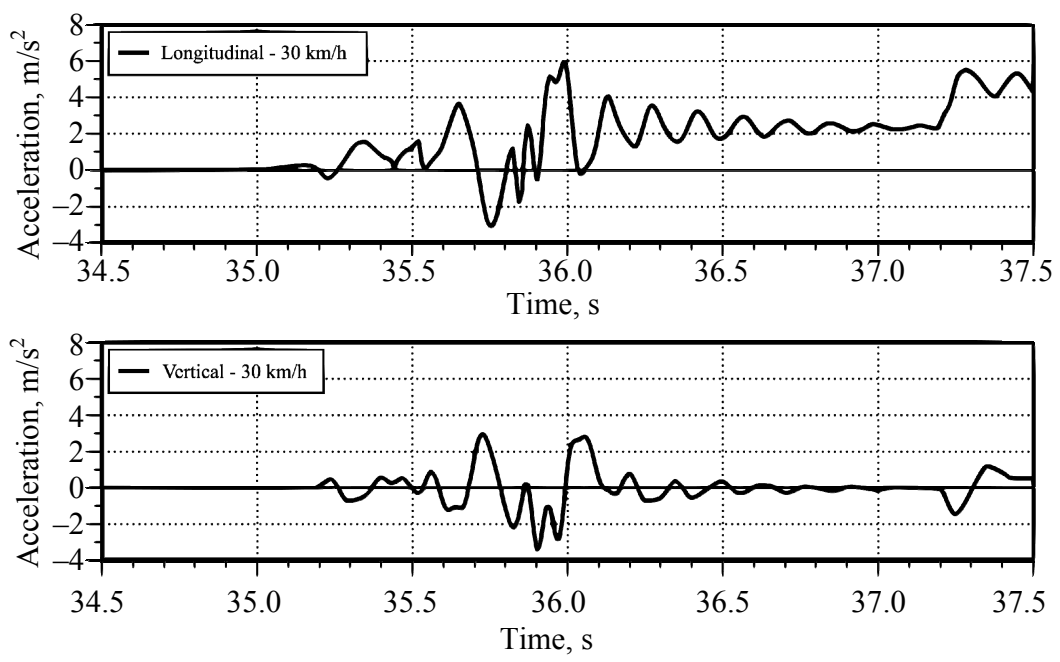

Fig. 5. Occurring accelerations at the seat rail during a Tip-In maneuver, starting at $30 \mathrm{~km} / \mathrm{h}$ 
Parameter variation of drive train components. In order to find out how the drivability in the tested driving scenarios can be improved, the parameters of selected drive train components of the simulation model were varied and the effects on the driving maneuvers were analyzed.

The effects were assessed on the basis of the driving maneuvers full-throttle acceleration from $0 \mathrm{~km} / \mathrm{h}$ to $100 \mathrm{~km} / \mathrm{h}$ (both gear changes and hybrid operation occurred), Tip-In at constant speed at $50 \mathrm{~km} / \mathrm{h}$ (gear changes occurred and Boost was active) and a Tip-Out after a constant speed at $130 \mathrm{~km} / \mathrm{h}$.

Following, an exemplary parameter variation of the clutch model is analyzed. In the clutch model, stiffness and damping coefficient of the torsional damper were varied, which is responsible that oscillation peaks of the ICE do not cause damage to the gearbox and ensure a smooth clutch engagement. The comfort values of the parameter variation for the three driving maneuvers are listed in Tab. 3.

Table 3

Comfort values for parameter variation of the clutch model

\begin{tabular}{|l|c|c|c|c|}
\hline \multirow{4}{*}{ Parameter } & \multirow{2}{*}{ Value } & \multicolumn{3}{|c|}{ Comfort value } \\
\cline { 3 - 5 } & & $\begin{array}{c}\text { Full-throttle } \\
\text { acceleration }\end{array}$ & Tip-In & Tip-Out \\
\hline \multirow{4}{*}{$\begin{array}{l}\text { Clutch stiffness, } \\
\text { Nm/rad }\end{array}$} & 500 & 1.202 & 1.438 & 0.143 \\
\cline { 2 - 5 } & 600 & 1.204 & 1.402 & 0.143 \\
\cline { 2 - 5 } & 700 & 1.206 & 1.371 & 0.143 \\
\cline { 2 - 5 } & 800 & 1.206 & 1.344 & 0.143 \\
\cline { 2 - 5 } & 900 & 1.209 & 1.323 & 0.143 \\
\cline { 2 - 5 } & 1000 & 1.215 & 1.307 & 0.143 \\
\cline { 2 - 5 } & 1100 & 1.218 & 1.294 & 0.143 \\
\hline \multirow{5}{*}{ Nm·s/rad } & 0 & 1.235 & 1.369 & 0.143 \\
\cline { 2 - 5 } & 0.5 & 1.203 & 1.355 & 0.143 \\
\cline { 2 - 5 } & 1.0 & 1.199 & 1.344 & 0.143 \\
\cline { 2 - 5 } & 1.5 & 1.199 & 1.335 & 0.143 \\
\cline { 2 - 5 } & 2.0 & 1.198 & 1.328 & 0.143 \\
\cline { 2 - 5 } & 2.5 & 1.198 & 1.323 & 0.143 \\
\cline { 2 - 5 } & 2.0 & 1.198 & 1.321 & 0.143 \\
\hline
\end{tabular}

It can be observed that the comfort value at full throttle acceleration increases (drivability decreases) proportional to the stiffness of the torsional damper, while during the Tip-In this tendency is opposite. During Tip-Out no change is detected.
Overall, drivability improves with increasing stiffness of the torsional damper during the simulated driving maneuvers. The variation of the damping coefficient shows similar results. With increasing damping, the comfort value decreases and thus drivability is improved.

Similarly, longer shifting times of the gearbox model increase the drivability. Although the driving comfort is increased in this case, the performance suffered and the acceleration from 0 to $100 \mathrm{~km} / \mathrm{h}$ requires more time. Increasing the stiffness of the drive shafts does not lead to the same effect as with the clutch. The comfort values increase in this case, but it should be noted that a minimum rigidity must be obtained when designing the shafts in order to transmit the full torque of the drive units to the wheels. For the wheel suspension no clear tendency of the comfort values can be recognized with variation of the spring stiffness. However, there is a range, in which the drivability is optimal. A stronger damping results in an overall improvement.

\section{CONCLUSIONS}

1. In this work, an approach is presented for the assessment and optimization of drivability of hybrid drive trains in virtual development processes. In the first step, various maneuvers for the drivability assessment were defined, which cover relevant driving situations for the comfort and performance assessment. Furthermore, objective drivability criteria and the corresponding measurable parameters were defined.

2. In the next step, the P2-hybrid drive train of a reference vehicle was modelled and parameterized with data acquired by measurements. In order to validate the model, comprehensive measurements were carried out on public roads and on a test track. The simulation model was then validated on the basis of the generated measurement data. Occurring differences between measurement and simulation at braking maneuvers were identified due to insufficient modelling of the brake. But if maneuvers without braking are to be analyzed, which is the case for most of the defined maneuvers, this model provides very good results. For a more precise representation of the drive train, it is necessary to have all data available, e. g. engine 
characteristics, efficiencies, positions and stiffnesses of engine bearings, maximum transmittable torque of clutches, rules of the hybrid operating strategy, etc.

3. By simulating different driving maneuvers, the resulting acceleration oscillations were calculated according to the VDI 2057-1 method and evaluated from the aspect of drivability. It turned out that gear changes at high gear ratios produce high acceleration amplitudes in the driver's seat rail and thus play a decisive role in the drivability assessment. The transition between hybrid and electric driving was also a trigger for peaks in the acceleration signal.

4. In order to identify the influencing factors of different maneuvers and parameters of the drive train components, both were varied. For instance, stiffer variants of the torsional damper of the clutch with higher damping and longer shifting times of the gearbox model improved drivability. Although the driving comfort was increased, the performance was affected and an acceleration from zero to $100 \mathrm{~km} / \mathrm{h}$ required more time. The simulation of driving maneuvers with optimized drivetrain setup often resulted in high comfort values, suggesting that there is potential for optimization of driving comfort.

5. Overall, change of gears and closing of the clutch had the greatest influence on the drivability and thus has the highest potential for optimizing the hybrid drive train. In this way, the introduced approach enables an assessment and optimization of drivability within a simulation environment and thus supports the development process of hybrid drive trains even in early project phases.

\section{REFERENCES}

1. Institute of Automotive Engineering, Graz University of Technology (2016-2018) KoMoT - Comfortable Mobility by Technology Integration. Available at: https://trimis.ec. europa.eu/project/comfortable-mobility-through-technolo gy-integration.
2. Gerson S., Matthies F., Jaensch D. Drivability Analysis of Tomorrow's Drive Trains in Real Road Traffic. IAV $\mathrm{GmbH}$, Berlin.

3. Specification of VW Passat GTE. Available at: https:// www. volkswagen.at/service-zubehoer/vorgaengermodelle/passatgte. (Accessed September 2019) (in German).

4. Fischer R., Kücükay F., Jürgens G. et al. (2012) Das Getriebebuch. Springer-Verlag. https://doi.org/10.1007/9783-7091-0877-2 (in German).

5. Albrecht M. (2005) Modelling of Comfort Ratings from a Customer's Point of View on the Example of the Automated Start-Up Procedure. Dissertation, University Karlsruhe (in German).

6. Matthies F. (2013) Contribution to the Modeling of Powertrains for Driveability Studies. Dissertation, Technical University of Berlin (in German).

7. The Association of German Engineers (2002) Human Exposure to Mechanical Vibrations - Whole-Body Vibration.

8. Glaser H., Renner M. (2002) The Chassis of the Audi A8. ATZ.

9. List H., Schöggl P. (1998) Objective Evaluation of Vehicle Driveability. SAE Technical Paper No 980204. https://doi. org/10.4271/980204.

10. AVL List GmbH (2008) AVL-DRIVE the Objective Tool for Driveability Assessment \& Development.

11. Rill G. (2008) Comparison of Integration Methods on an Example from Vehicle Dynamics. University of Regensburg (in German).

12. Siemens PLM Software - Simcenter Amesim. Available at: https://www.plm.automation.siemens.com/global/de/produ cts/simcenter/simcenter-amesim.html. (Accessed September 2019).

13. Domijanic M., Hirz M. (2019) Simulation Models for the Assessment of the Influence of Driver Behavior on the Control of xEV Drive Trains. International Vienna Motor Symposium (in German).

14. Automotive Dynamic Motion Analyzer (ADMA). Available at: https://www.genesys-offenburg.de/en/products/admaspeed-speed-and-braking-distance-sensor/. (Accessed September 2019).

15. Dewetron Measurement Computer. Available at: https:// www.dewetron.com/products/data-acquisition-hardwarechassis/. (Accessed September 2019).

16. Domijanic M. (2018) Influence of Driver Behavior on the Efficiency-Optimal Control of xEV Drive Trains. Report, Institute of Automotive Engineering, Graz University of Technology (in German).

Received: 08.10.2019

Accepted: 10.12 .2019 Published online: 29.01.2021 